\title{
Recovery of spores of Clostridium difficile altered by heat or alkali
}

\author{
S. KAMIYA*, K. YAMAKAWA, H. OGURA and S. NAKAMURA
}

\section{Department of Bacteriology, School of Medicine, Kanazawa University, Kanazawa, Japan}

\begin{abstract}
Summary. The effect of heating or alkali-treatment on spore recovery in ordinary growth medium was examined for four strains of Clostridium difficile. Heating spores at $80^{\circ} \mathrm{C}$ for $10 \mathrm{~min}$ produced $95.50-99.95 \%$ decreases in the recovery rates. Treatment with $0.1 \mathrm{~N} \mathrm{NaOH}$ for 15 min produced 99.47 and $99.83 \%$ decreases in spore recovery rates for two of the four strains. The influence of either addition of lysozyme after treatment with sodium thioglycollate (thioglycollate-lysozyme method) or addition of sodium taurocholate (taurocholate method) on recovery of heat- or alkali-treated $C$. difficile spores was also examined. Viable spores of all strains altered by heating at $90^{\circ} \mathrm{C}$ or $100^{\circ} \mathrm{C}$ for 10 min could not be recovered at all by the taurocholate method. Nor did this method allow recovery of alkali-altered spores treated with $>0.2 \mathrm{~N}$ $\mathrm{NaOH}$ for $15 \mathrm{~min}$. On the other hand, $10-47 \%$ of altered spores heated at $90^{\circ} \mathrm{C}$ for 10 min were recovered by the thioglycollate-lysozyme method, and alkali-altered spores treated with $0 \cdot 1-0.3 \mathrm{~N} \mathrm{NaOH}$ for 15 min were as completely recovered by this method as untreated spores. These results indicate that the thioglycollate-lysozyme method is more effective than the taurocholate method for recovery of the heat- or alkali-altered C. difficile spores.
\end{abstract}

\section{Introduction}

Clostridium difficile is a major cause of pseudomembranous colitis and of many cases of antibioticassociated diarrhoea (Bartlett et al., 1978; George et al., 1978; Larson et al., 1978; Borriello and Larson, 1981). Environmental contamination has been suggested as a significant factor in the transmission of $C$. difficile (Fekety et al., 1980; Larson et al., 1980). Survival of $C$. difficile in an aerobic environment is possible because this obligate anaerobe can form aerotolerant spores; there are reports that $C$. difficile can survive for $>5$ months in aerobic conditions (Kim et al., 1981). Although it is well known that $C$. difficile spores cannot be effectively recovered in ordinary growth medium (Raibaud et al., 1980), their recovery is distinctly enhanced when they are treated with sodium thioglycollate and inoculated in lysozyme containing media (Ionesco, 1978; Nakamura et al., 1985). It has also been reported that addition of sodium taurocholate to media resulted in good

Received 19 Aug. 1988; accepted 31 Aug. 1988.

* Address for correspondence and offprints: Dr S. Kamiya, Department of Bacteriology, School of Medicine, Kanazawa University, Kanazawa, Ishikawa 920, Japan. spore recovery (Raibaud et al., 1980; Wilson et al., 1982) and sodium taurocholate-containing medium has been shown to be useful for detection of $C$. difficile spores, particularly when faecal specimens have not been handled optimally or when vegetative forms have lost viability after prolonged exposure to air (Buggy et al., 1983, 1985; Wilson, 1983). It is possible that spores present in clinical specimens or on environmental surfaces may be altered by various kinds of physicochemical damage after aerobic exposure.

In the present study, the effects of heat or alkali treatment on $C$. difficile spores were examined and the influence of thioglycollate-lysozyme or sodium taurocholate on their recovery was assessed.

\section{Materials and methods}

\section{Bacterial strains and preparation of spore suspensions}

C. difficile strains $\mathrm{KZ} 1610, \mathrm{KZ} 1628, \mathrm{KZ} 1648$ and $\mathrm{KZ} 1660$ were isolated in this laboratory from faecal specimens of patients with antibiotic-associated diarrhoea (Nakamura et al., 1980). Preliminary findings showed that strains KZ 1660 and $\mathrm{KZ} 1610$ had exceptionally high spore-recovery rates, i.e., $>10 \%$, when assayed in ordinary GS-BHI medium (see below) 
after heating at $70^{\circ} \mathrm{C}$ for $10 \mathrm{~min}$. In contrast, strains $\mathrm{KZ}$ 1628 and $\mathrm{KZ} 1648$ had very low spore-recovery rates of $<0.01 \%$. Spores were produced in Brain Heart Infusion broth (BHI; BBL Microbiology System, Cockeysville, $\mathrm{MD}$, USA) supplemented with $\mathrm{Na}_{2} \mathrm{HPO}_{4} 0.2 \% \mathrm{w} / \mathrm{v}$ (m-BHI) as described before (Nakamura et al., 1985). Briefly, $0.1 \mathrm{ml}$ of an 18-h culture of each strain in liver broth was inoculated into $10 \mathrm{ml}$ of $\mathrm{m}-\mathrm{BHI}$ and incubated anaerobically at $37^{\circ} \mathrm{C}$ for 5 days. Cultures were centrifuged at $3500 \mathrm{~g}$ for $5 \mathrm{~min}$, and pellets resuspended in appropriate volumes of distilled water to yield $(0.5-1 \cdot 0) \times$ $10^{7}$ spores $/ \mathrm{ml}$; these suspensions were heated at $70^{\circ} \mathrm{C}$ for $10 \mathrm{~min}$ to kill vegetative cells. For the experiment of recovery of heated spores at $60^{\circ} \mathrm{C}$, the spore suspension was obtained by heating $C$. difficile culture at $60^{\circ} \mathrm{C}$ for 10 $\min$.

\section{Quantitative determination of spores and vegetative cells}

Quantitative determinations of heat- or alkali-treated spores and vegetative cells were made with pour plates incorporating GS-BHI medium-BHI (Nissui, Tokyo, Japan) supplemented with glucose $0.8 \% \mathrm{w} / \mathrm{v}$, soluble starch $1 \% \mathrm{w} / \mathrm{v}, \mathrm{L}$-cysteine- $\mathrm{HCl} 0.05 \% \mathrm{w} / \mathrm{v}$ and agar $1.3 \%$ $\mathrm{w} / \mathrm{v}$ as described by Nakamura et al. (1985). A $0 \cdot 1-\mathrm{ml}$ amount of each 10-fold dilution of spore suspension in BHI broth suppplemented with L-cysteine- $\mathrm{HCl} 0.05 \%$ $\mathrm{w} / \mathrm{v}$ was pipetted into $9-\mathrm{cm}$ diameter petri dishes and mixed with $20 \mathrm{ml}$ of GS-BHI agar. Inoculated agar plates were incubated anaerobically at $37^{\circ} \mathrm{C}$ for $72 \mathrm{~h}$.

\section{Preparation of heat-treated spores}

For heat-treatment, $3.0 \mathrm{ml}$ of spore suspension in Pyrex tubes $(9 \times 150 \mathrm{~mm})$ was heated at $60^{\circ}, 70^{\circ}, 75^{\circ}, 80^{\circ}, 85^{\circ}$, $90^{\circ}$ or $100^{\circ} \mathrm{C}$ for $10 \mathrm{~min}$. When heating at $90^{\circ} \mathrm{C}$ or $100^{\circ} \mathrm{C}$, an oil bath was used. The tubes were cooled immediately in ice water and surviving spores enumerated as described above.

\section{Preparation of alkali-treated spores}

This was based on the method described by Duncan $e t$ al. (1972). Spore suspensions $(3.0 \mathrm{ml})$ of each strain were treated with $\mathrm{NaOH}-0.05,0 \cdot 1,0 \cdot 2$ or $0.3 \mathrm{~N}$ for $15 \mathrm{~min}$ at $4{ }^{\circ} \mathrm{C}$. Thereafter, spores were washed three times, and resuspended in an equal volume of cold distilled water. Quantitative determination of numbers of spores was made as described above.

\section{Recovery of heat- or alkali-treated spores}

Two different methods for recovery of heat- or alkalitreated $C$. difficile spores were employed. The first, the thioglycollate-lysozyme method, involves addition of lysozyme after treatment with sodium thioglycollate, and has been described before (Ionesco, 1978; Nakamura et al., 1985). Three volumes of spore suspensions were mixed with one volume of $2 \mathrm{M}$ sodium thioglycollate, adjusted to $\mathrm{pH} 10.0$ with $5 \mathrm{~N} \mathrm{NaOH}$ and incubated at $50^{\circ} \mathrm{C}$ for $30 \mathrm{~min}$. The treated samples were diluted and inoculated into GS-BHI agar medium containing lysozyme (egg white $\times 6$ crystallised, Seikagaku Kogyo Co. Ltd, Tokyo) $10 \mu \mathrm{g} / \mathrm{ml}$. The second method utilising sodium taurocholate was as described by Raibaud et al. (1980) and Wilson et al. (1982). Briefly, 0.1 ml of each 10fold dilution of spore suspension was pipetted into $9-\mathrm{cm}$ petri dishes and mixed with $20 \mathrm{ml}$ of GS-BHI agar medium containing sodium taurocholate $0.1 \% \mathrm{w} / \mathrm{v}$ (guaranteed reagent grade, Nakarai Chemicals Ltd, Kyoto, Japan) and was prepared before use as described by Kamiya et al. (1987). The relative recovery rate (\%) of spores was expressed as the ratio of the number of colonies recovered by either method after heat- or alkalitreatment to that of colonies recovered by the taurocholate method after heating at $70^{\circ} \mathrm{C}$ for $10 \mathrm{~min}$, a technique which yields nearly $100 \%$ recovery (Kamiya et al., 1987).

\section{Results}

\section{Determination of temperature and concentration of $\mathrm{NaOH}$ altering $\mathrm{C}$. difficile spores}

By incubation of heat- or alkali-treated spores of C. difficile in ordinary GS-BHI medium, the temperature and concentration of $\mathrm{NaOH}$ which altered $C$. difficile were determined. With all strains there was a considerable decline in the relative recovery rates of their spores when heated at $80^{\circ} \mathrm{C}$ for $10 \mathrm{~min}$ (fig. 1A). Thus, the spores of strains $\mathrm{KZ}$
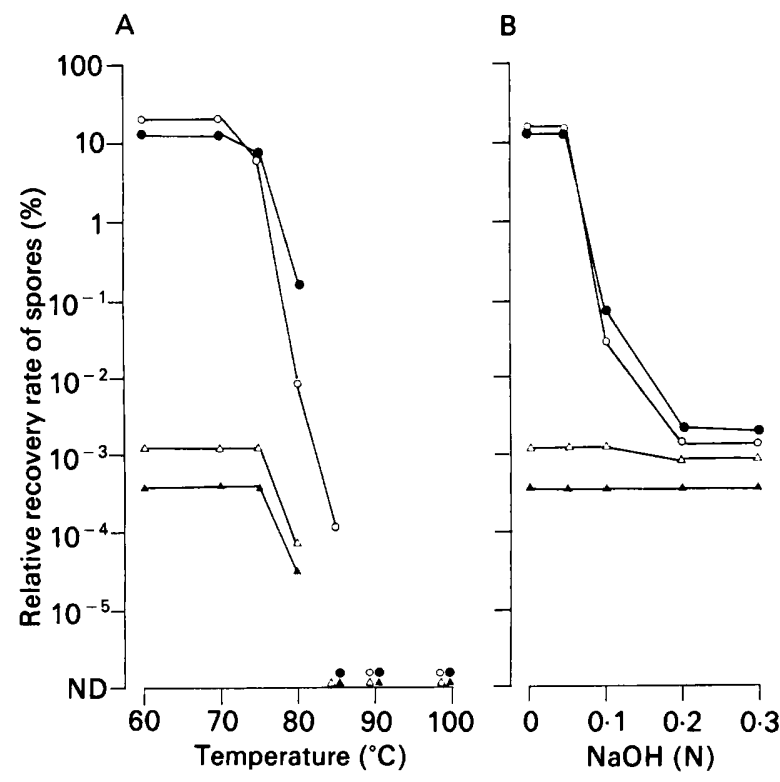

Fig. 1. Recovery of heat- or alkali-treated spores of $C$. difficile strains in GS-BHI agar medium: A, heat-treated; B, alkalitreated. Strains: O, KZ 1660;, $\mathrm{KZ} 1610 ; \triangle, \mathrm{KZ} 1648 ; \Delta$ KZ 1628. ND = not detected. 
1660, KZ 1610, KZ 1628 and $\mathrm{KZ} 1648$ showed decreases in their recovery rates of $99.95,98.84$, 97.82 and $95.50 \%$ respectively. After heating at $85^{\circ} \mathrm{C}$, the spores of strain $\mathrm{KZ} 1660$ germinated with a very low recovery rate of $0.0001 \%$, and those of the other strains could not be recovered at all. None of the strains germinated when the spores were heated at $90^{\circ}$ or $100^{\circ} \mathrm{C}$ for $10 \mathrm{~min}$.

When the spores were treated with $0.1 \mathrm{~N} \mathrm{NaOH}$ for $15 \mathrm{~min}$, the relative recovery rates of strains $\mathrm{KZ}$ 1610 and $\mathrm{KZ} 1660$ decreased remarkably to 0.063 and $0.025 \%$ respectively (fig. $1 \mathrm{~B}$ ). In this experiment, strains KZ 1628 and $\mathrm{KZ} 1648$ showed no considerable decreases in their relative recovery rates even when the spores were treated with $0.3 \mathrm{~N}$ $\mathrm{NaOH}$. These results suggest that the determinative conditions of heating or alkali-treatment that alter C. difficile spores are $80^{\circ} \mathrm{C}$ or $0.1 \mathrm{~N} \mathrm{NaOH}$, respectively.

Recovery of heat-or alkali-altered spores by the taurocholate method

Recovery rates of heat- or alkali-treated spores were examined by the taurocholate method. When heated at $60^{\circ} \mathrm{C}, 70^{\circ} \mathrm{C}$ or $75^{\circ} \mathrm{C}$ for $10 \mathrm{~min}$, the spores of strains $\mathrm{KZ} 1628$ and $\mathrm{KZ} 1648$ could be recovered as effectively as those of strains $\mathrm{KZ} 1610$ and $\mathrm{KZ}$ 1660 (fig. $2 A$ ). It was also shown that the relative recovery rates of the spores were considerably decreased by heating at $80^{\circ} \mathrm{C}$ for $10 \mathrm{~min}$ to $2 \cdot 9,2 \cdot 1$, 0.73 and $0.05 \%$ for strains $\mathrm{KZ} 1628, \mathrm{KZ} 1648, \mathrm{KZ}$
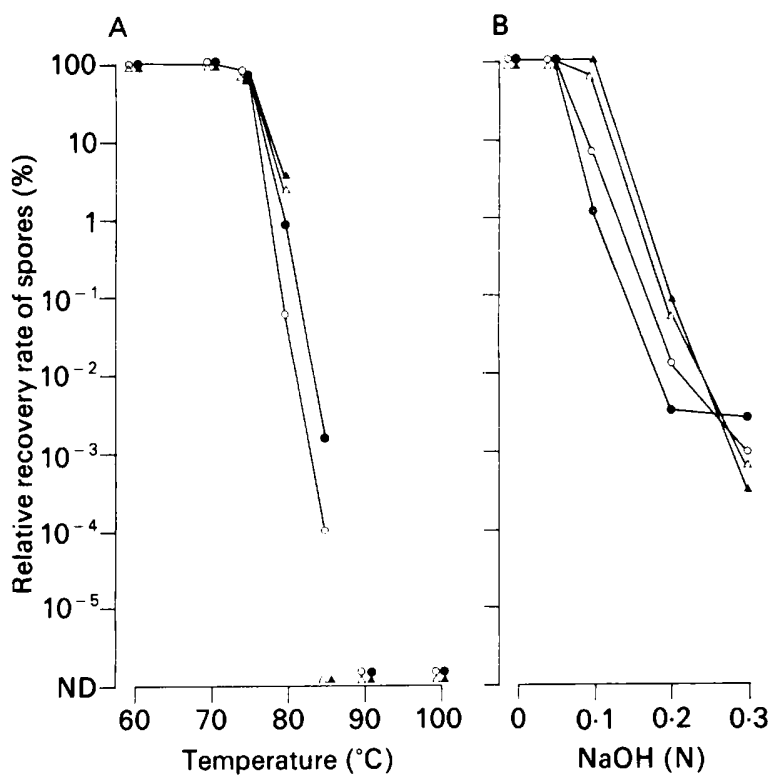

Fig. 2. Recovery of heat- or alkali-treated spores of $C$. difficile by the taurocholate method: A, heat-treated; $B$, alkali-treated. Strains: O, KZ 1660; O, KZ 1610;, KZ 1648; $\boldsymbol{A}, \mathrm{KZ} 1628$. $\mathrm{ND}=$ not detected.
1610 and $\mathrm{KZ} 1660$, respectively. Heating the spores at $85^{\circ} \mathrm{C}$ for $10 \mathrm{~min}$ resulted in further decreases in the relative recovery rates to 0.0015 and $0.0001 \%$, for strains KZ 1610 and KZ 1660; the spores of the other two strains could not be recovered at all. After heating at $90^{\circ}$ or $100^{\circ} \mathrm{C}$ for $10 \mathrm{~min}$, none of the strains was recovered by this method. It was similarly noted that the alkali-treated spores could not be recovered effectively by the taurocholate method (fig. 2B). When treated with $0.1 \mathrm{~N} \mathrm{NaOH}$, the relative recovery rates of spores of strains $\mathrm{KZ}$ 1660 and $\mathrm{KZ} 1610$ were decreased to 5.9 and $1.3 \%$, respectively, although spores of strains $\mathrm{KZ} 1628$ and $\mathrm{KZ} 1648$ were relatively resistant. In contrast, treatment with $0.2 \mathrm{~N} \mathrm{NaOH}$ for 15 min reduced remarkably the relative recovery rates of all strains to levels of $0.0034-0.074 \%$. From these results, the taurocholate method was shown to be ineffective for recovery of heat- or alkali-altered spores of $C$. difficile.

\section{Recovery of heat-or alkali-altered spores by the thioglycollate-lysozyme method}

We next examined the effect of the thioglycollatelysozyme method on recovery of heat- or alkalialtered $C$. difficile spores. The relative recovery rates of heat-altered spores at $80^{\circ}$ or $85^{\circ} \mathrm{C}$ were not decreased considerably (fig. 3A). By heating at $90^{\circ} \mathrm{C}$ for $10 \mathrm{~min}$, the relative recovery rates of the strains were $10 \cdot 0-47 \cdot 2 \%$. Heating of the spores at $100^{\circ} \mathrm{C}$ for $10 \mathrm{~min}$, however, reduced the relative recovery rates to $2 \cdot 1,1 \cdot 8,0 \cdot 21$ and $0 \cdot 20 \%$ for strains $\mathrm{KZ} 1660, \mathrm{KZ} 1648$, KZ 1628 and KZ 1610, respectively. In contrast, complete recovery of the alkali-altered spores of $C$. difficile was demonstrated in the thioglycollate-lysozyme method (fig. 3B). There were no decreases in recovery rates of the spores of any strains even when the spores were treated with $0.3 \mathrm{~N} \mathrm{NaOH}$ for $15 \mathrm{~min}$. These results indicate that the thioglycollate-lysozyme method is effective for recovery of heat- or alkali-altered spores of $C$. difficile.

\section{Discussion}

The effect of heating or alkali-treatment on recovery of the spores of four strains of $C$. difficile was examined in ordinary GS-BHI medium. The determinative temperature which altered $C$. difficile spores was shown to be $80^{\circ} \mathrm{C}$ for all strains. This temperature was lower than that which altered $C$. perfringens spores (Duncan et al., 1972). The spores of $C$. perfringens are heat-resistant at temperatures between $80^{\circ}$ and $100^{\circ}$ (Robert, 1968; Duncan et al., 1972) and treatment of spores at ultrahigh temper- 
A

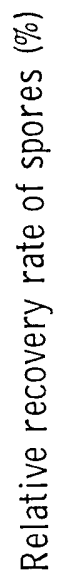

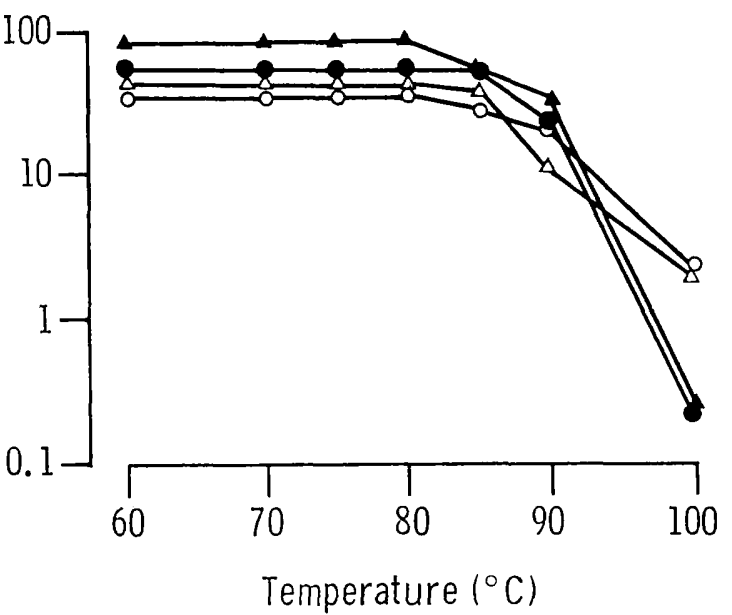

B

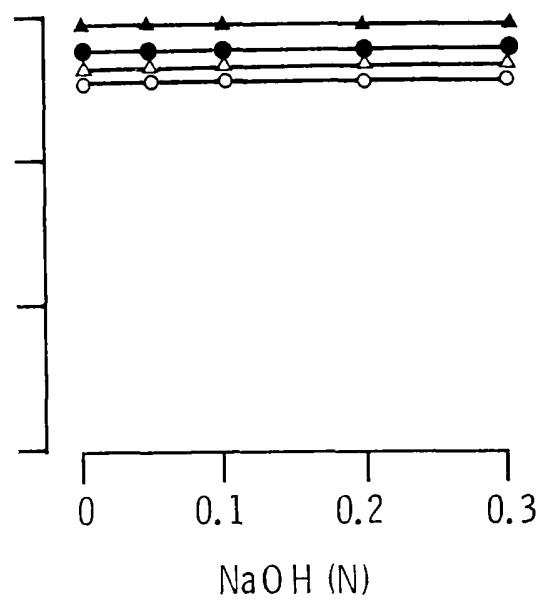

Fig. 3. Recovery of heat- or alkali-treated spores of $C$. difficile by the thioglycollate-lysozyme method: A, heat-treated; B, alkalitreated. Strains: $\mathrm{O}, \mathrm{KZ} 1660 ; \bigcirc, \mathrm{KZ} 1610 ; \triangle, \mathrm{KZ} 1648 ; \Delta, \mathrm{KZ} 1628$.

ature, i.e., $>100^{\circ} \mathrm{C}$, is required for their inactivation (Adams, 1973). It has also been reported that treatment of $C$. perfringens spores with $0.1 \mathrm{~N} \mathrm{NaOH}$ for $15 \mathrm{~min}$ resulted in considerable decrease in germination of spores (Duncan et al., 1972). In this study, similarly, the treatment of $C$. difficile spores with $0 \cdot 1-0.3 \mathrm{~N} \mathrm{NaOH}$ resulted in a remarkable decrease in the recovery rate of spores, although strains KZ 1628 and KZ 1648, which showed very low recovery rate even when untreated, did not show any decrease in spore recovery by alkalitreatment.

Two different methods, the thioglycollate-lysozyme method (Ionesco, 1978; Nakamura et al., 1985) and taurocholate method (Raibaud et al., 1980; Wilson et al., 1982) have been reported to be effective in the recovery of $C$. difficile spores. The thioglycollate-lysozyme method performed in the present study contained two sequential procedures - treatment of the spores with sodium thioglycollate at $50^{\circ} \mathrm{C}$ for 30 min followed by addition of lysozyme at a final concentration of $10 \mu \mathrm{g} / \mathrm{ml}$. The former was shown to rupture disulphide bonds in the spore coat allowing lysozyme to penetrate into the spore cortex, and the latter is thought to attack the underlying mucopeptide of the spore cortex releasing hexosamine peptides as end products (Gould and Hitchins, 1965; Gould and King, 1969). There have been no reports on the mechanism for the augmentation of outgrowth of $C$. difficile spores in the presence of sodium taurocholate but it is possible that it plays an important role as a detergent attacking the spore coat or cortex.

With regard to the efficiency of the recovery rate of $C$. difficile spores, the thioglycollate-lysozyme method was shown to be slightly less effective than the taurocholate method for untreated spores (Kamiya et al., 1987). However, in the present study, it was clearly shown that the heat- or alkalialtered $C$. difficile spores could be recovered by the thioglycollate-lysozyme method but not at all by the taurocholate method.

Kim et al. (1981) detected C. difficile on various hospital environmental surfaces (bedpans, toilet seats and floors) in both a patient room and a soiled utility room, not only in an adult intensive-care unit associated with cases of $C$. difficile colitis but also in a control unit. They also showed that $10^{6} \mathrm{cfu}$ of $C$. difficile inoculated on to the floor of an unused room could survive exposure for $>5$ months. Buggy et al. $(1983,1985)$ stated that addition of sodium taurocholate to a selective medium effected recovery of $C$. difficile spores from environmental surfaces. However, it is possible that $C$. difficile spores taken from different environmental surfaces might have suffered various kinds of physicochemical damage. It is possible, therefore, that the thioglycollate-lysozyme method would be more effective than the taurocholate method for recovery of these spores. Further investigations are required to clarify the mechanism(s) by which heat-or alkalialtered $C$. difficile spores can be recovered by the thioglycollate-lysozyme method but not by the taurocholate method.

We are very grateful to Dr S. P. Borriello, Microbial Pathogenicity Research Group, Clinical Research Centre, Harrow, UK, for critical advice during the preparation of this manuscript. 


\section{REFERENCES}

Adams D M 1973 Inactivation of Clostridium perfringens type A spores at ultrahigh temperatures. Applied Microbiology 26: 282-287.

Bartlett J G, Chang T W, Gurwith M, Gorbach S L, Onderdonk A B 1978 Antibiotic-associated pseudomembranous colitis due to toxin-producing clostridia. New England Journal of Medicine 298: 531-534.

Borriello S P, Larson H E 1981 Antibiotics and pseudomembranous colitis. Journal of Antimicrobial Chemotherapy 7 Suppl A : 53-62.

Buggy B P, Hawkins C C, Fekety R 1985 Effect of adding sodium taurocholate to selective media on the recovery of Clostridium difficile from environmental surfaces. Journal of Clinical Microbiology 21 : 636-637.

Buggy B P, Wilson K H, Fekety R 1983 Comparison of methods for recovery of Clostridium difficile from an environmental surface. Journal of Clinical Microbiology 18 : 348-352.

Duncan C L. Labbe R G, Reich R R 1972 Germination of heatand alkali-altered spores of Clostridium perfringens type $\mathrm{A}$ by lysozyme and an initiation protein. Journal of Bacteriology 109: 550-559.

Fekety R et al. 1980 Studies on the epidemiology of antibioticassociated Clostridium difficile colitis. American Journal of Clinical Nutrition 33 Suppl : 2527-2532.

George W L, Sutter V L, Goldstein E J C Ludwig S L Finegold S M 1978 Aetiology of antimicrobial agent-associated colitis. Lancet 1 : 802-803.

Gould G W, Hitchins A D 1965 Germination of spores with Strange and Dark's spore lytic enzyme. In: Campbell L L, Halvorson H O (eds) Spores III. American Society for Microbiology, Ann Arbor, pp 213-221.

Gould G W, King W L 1969 Action and properties of spore germination enzymes. In: Campbell L L (ed) Spores IV. American Society for Microbiology, Bethesda, pp 276-286. Ionesco H 1978 Initiation de la germination des spores de
Clostridium difficile par le lysozyme. Comptes Rendus des Séances de l'Academie des Sciences, Série D: Sciences Naturelles (Paris) 287: 659-661.

Kamiya S, Yamakawa K, Ogura H, Nakamura S 1987 Effect of various sodium taurocholate preparations on the recovery of Clostridium difficile spores. Microbiology and Immunology 31 : $1117-1120$.

Kim K H et al. 1981 Isolation of Clostridium difficile from the environment and contacts of patients with antibioticassociated colitis. Journal of Infectious Diseases 143: 42-50.

Larson H E, Price A B, Borriello S P 1980 Epidemiology of experimental enterocecitis due to Clostridium difficile. Journal of Infectious Diseases 142 : 408-413.

Larson H E, Price A B, Honour P, Borriello S P 1978 Clostridium difficile and the aetiology of pseudomembranous colitis. Lancet 1 : 1063-1066.

Nakamura S, Nakashio S, Inamatsu T, Nishida N, Taniguchi N, Nichida S 1980 Toxigenicity of Clostridium difficile isolates from patients and healthy adults. Microbiology and Immunology 24: 995-997.

Nakamura S, Yamakawa K, Izumi J, Nakashio S, Nishida S 1985 Germinability and heat resistance of spores of Clostridium difficile strains. Microbiology and Immunology 29: 113-118.

Raibaud P, Ducluzeau R, Dubos F, Hudault S, Bewa H, Muller M C 1980 Implantation of bacteria from the digestive tract of man and various animals into gnotobiotic mice. American Journal of Clinical Nutrition 33 Suppl: 2440-2447.

Roberts T A 1968 Heat and radiation resistance and activation of spores of Clostridium welchii. Journal of Applied Bacteriology 31 : 133-144.

Wilson K H 1983 Efficiency of various bile salt preparations for stimulation of Clostridium difficile spore germination. Journal of Clinical Microbiology 18: 1017-1019.

Wilson K H, Kennedy M J, Fekety F R 1982 Use of sodium taurocholate to enhance spore recovery on a medium selective for Clostridium difficile. Journal of Clinical Microbiology 15: 443-446. 